\title{
Comparison of linuron degradation in the presence of pesticide mixtures in soil under laboratory conditions
}

\author{
Maria Swarcewicz • Andrzej Gregorczyk • \\ Justyna Sobczak
}

Received: 14 June 2012 / Accepted: 28 February 2013 /Published online: 23 March 2013

(C) The Author(s) 2013. This article is published with open access at Springerlink.com

\begin{abstract}
It is widely recognised that complex interactions occur between chemicals in mixtures. In many agricultural situations, the use of tank mixes and complex spray programs is a common practice. Insecticides, fungicides and a herbicide being applied in potato protection were used in this research. Interactions between linuron and insecticides, such as thiamethoxam or clothianidin, and fungicides, such as mancozeb or chlorothalonil, were examined in soil. The degradation rate of linuron in soil during laboratory incubation in six treatments was studied. Mixtures of linuron with mancozeb in sandy loam and clay loam soils had a significant effect on the persistence of this herbicide. For example, for the same herbicide, $t_{1 / 2}$ values for linuron were from 37 days in sandy loam to 44 days in clay loam. These values changed (64-67 days) when thiamethoxam and mancozeb were in soil. When mancozeb was added only, the half-life values were
\end{abstract}

M. Swarcewicz $(\bowtie) \cdot$ J. Sobczak

Institute of Organic Chemical Technology,

Department of Organic Synthesis and Drug Technology,

West Pomeranian University of Technology,

42 Piastów Ave,

71-065 Szczecin, Poland

e-mail: mswar@zut.edu.pl

A. Gregorczyk

Faculty of Environment Management and Agriculture,

Department of Agronomy, West Pomeranian

University of Technology,

3 Pawła VI St,

71-459 Szczecin, Poland from 59 to 62 days, respectively. Other mixtures with chlorothalonil, thiamethoxam and clothianidin did not have any effect. In order to compare linuron degradation rates in soils, a single first-order model and expanded statistical analysis were used.

Keywords Clothianidin · Chlorothalonil · Linuron · Mancozeb · Mixture $\cdot$ Soil $\cdot$ Thiamethoxam

\section{Introduction}

Among pesticides, the family of phenylurea herbicides has received particular attention in recent years because of its high biotoxicity and possible carcinogenic properties. Moreover, these compounds require several weeks, or even months, to be removed from the environment, inhibit photosynthesis and are widely used to control weeds in different crops. Linuron [3-(3,4-dichlorophenyl)-1-methoxy-1methyl urea] is a selective $N$-methoxy- $N$-methyl substituted phenylurea that is considered to be moderately to highly toxic to aquatic organisms (Orme and Kegley 2006). In addition, linuron is suspected to act as an antagonist for androgen receptor affecting the male reproductive system and therefore is also of concern for human health (McIntyre et al. 2002). Although linuron is moderately persistent and relatively immobile in soil, runoff and leaching can result in the migration of this compound to surface and groundwater bodies, with attendant 
environmental risks (U.S. EPA 1995). Therefore, understanding of the natural attenuation of linuron in the environment is important. Under field conditions, the half-life time for linuron varies from 30 to 150 days for different soil types, with an estimated average half-life of 60 days (U.S. EPA 1984).

Linuron is a hydrophobic herbicide that has been increasingly detected in surface and ground water and is mainly adsorbed by the organic matter fraction of soil (Sánchez-Martin et al. 2003; Sánchez-Camazano et al. 2000).

In many agricultural situations, the use of tank mixes and complex spray programs is a common practice (Fogg et al. 2003). It is known that due to several pesticide applications in one vegetation season, a pesticide may be present in mixtures with other pesticides or xenobiotics in soil. There is evidence that the persistence of a number of pesticides may be changed when used in combination with other pesticides (Walker 1970; Karanth et al. 1984; Swarcewicz and Gregorczyk 2012). Insecticides, fungicides and a herbicide being applied in potato protection were used in this research. Potential interactions between linuron and insecticides, such as thiamethoxam and clothianidin, and fungicides, such as mancozeb and chlorothalonil, were examined in soil. The objective of this research was to compare the degradation rate of linuron with five pesticides mixtures in soil using a single first-order model and expanded statistical analysis. The selection of linuron as a model herbicide was somehow arbitrary, except that it was widely used in Poland for many years and its residues can be still found in the environment.

\section{Materials and methods}

Sampling and soil materials

Commercial formulations of linuron (Linurex $500 \mathrm{SC}$, $500 \mathrm{~g}$ a.i. $\cdot \mathrm{L}^{-1}$, Makhteshim Agan Industries Ltd.), thiamethoxam (Actara $25 \mathrm{WG}, 25 \mathrm{~g}$ a.i. $\cdot \mathrm{kg}^{-1}$, Syngenta Crop Protection AG), clothianidin (Apacz 50 WG, $50 \mathrm{~g}$ a.i. $\mathrm{kg}^{-1}$, Arysta LifeSciences), mancozeb (Indofil 80 WP, $80 \mathrm{~g}$ a.i. $\mathrm{kg}^{-1}$, Arysta LifeSciences), chlorothalonil (Gwarant $500 \mathrm{SC}, 500 \mathrm{~g}$ a.i. $\cdot \mathrm{L}^{-1}$, Arysta LifeSciences) and the analytical grade of linuron were used throughout the study. Two soils were used in all analyses. The first soil was a sandy loam from Lipnik with textural composition of $72 \%$ sand, $16 \%$ silt and $12 \%$ clay. This soil had a $\mathrm{pH}$ of 6.4 in $\mathrm{CaCl}_{2}$, organic matter $1.7 \%$ and cation exchange capacity of $2.20 \mathrm{cmol} \cdot \mathrm{kg}^{-1}$. The second soil, from Ostoja, was a clay loam with $40 \%$ sand, $34 \%$ silt and $26 \%$ clay and $1.5 \%$ organic matter, and a $\mathrm{pH}$ of 6.3. Both soils are commonly used in agricultural production, and all soil characteristics being presented describe the 0 - to $10-\mathrm{cm}$ soil horizon, air dried and finally screened through a $3-\mathrm{mm}$ sieve.

\section{Procedure}

Soil portions (450 g) were treated with aqueous solution of linuron and five mixtures of linuron with (1) mancozeb, (2) chlorothalonil, (3) thiamethoxam, (4) clothianidin and (5) thiamethoxam and mancozeb. All treatments were replicated three times. The persistence of linuron in soil under laboratory conditions was analysed using a concentration of $2 \mathrm{mg} \cdot \mathrm{kg}^{-1}$ airdried soil, while that of mancozeb, chlorothalonil, thiamethoxam and clothianidin at 2.1, 2.0, 10 and $5 \mathrm{mg} \cdot \mathrm{kg}^{-1}$, respectively. The pesticide solutions were used to adjust the water content of soil to $60 \%$ of field capacity. After mixing the soil, samples were transferred into jars and incubated at $22{ }^{\circ} \mathrm{C} \pm 2{ }^{\circ} \mathrm{C}$. The jars were opened once a week, for the sake of aeration, and the water content was adjusted by weighing. Three $50 \mathrm{-g}$ samples of each treatment were taken for the analysis of herbicide residues $1 \mathrm{~h}$ after initial mixing and 1, 10, 20, 30, 40, 70 and 90 days after treatment. A 5.0-g portion of each sample was taken for moisture measurement, and 50-g soil samples were shaken for $1 \mathrm{~h}$ on a wristaction shaker with $100 \mathrm{~mL}$ of methanol. After shaking, the soil was allowed to remain in contact with the solvent for further $20 \mathrm{~h}$ before being shaken for another 1-h extraction period.

Analytical method

The concentration of linuron in the filtrate was determined using the HPLC. The analysis was performed on a Waters 600E HPLC chromatographic system equipped with PAD (UV) detector, Waters Nova Pack C18 column $(3.9 \times 150 \mathrm{~mm}), 60 \AA$ and packing size $4 \mu \mathrm{m}$. The UV detection was performed while set to $249 \mathrm{~nm}$. For the analysis, the mobile phase consisted of $\mathrm{MeOH} /$ water $(80: 20 \mathrm{v} / \mathrm{v})$. The flow rate was $1 \mathrm{~cm}^{3} \cdot \mathrm{min}^{-1}$, volume injected $5 \mu \mathrm{L}$. A HP Waters Millenium Software data system was used to collect, integrate and analyse the chromatographic data. The limit of determination was 
$0.012 \mathrm{mg} \cdot \mathrm{kg}^{-1}$, the efficiency of recovery was $82 \pm 8 \%$ ( \pm RSD), and the detection limit was $0.005 \mathrm{mg} \cdot \mathrm{kg}^{-1}$.

\section{Statistical procedures}

The kinetic of herbicide decomposition in soil can be reasonably well described by the first-order equation (SFO model): $C=C_{0} \exp (-k t)$, where $C$ - concentration after time $t\left(\mathrm{mg} \cdot \mathrm{kg}^{-1}\right), C_{0}$-initial concentration $\left(\mathrm{mgkg}^{-1}\right), k$-rate constant $\left(\right.$ days $\left.^{-1}\right)$ and $t$ - time (days) (Kah et al. 2007; Beulke et al. 2000). The time for $50 \%$ disappearance of linuron in soil $\left(t_{1 / 2}\right)$ was obtained from the following equation: $t_{1 / 2}=\ln 2 / k$. The second parameter was $\mathrm{DT}_{90}=\ln 10 / k$. The estimates of mathematical model parameters were found using the Levenberg-Marquardt non-linear method (loss function: minimum of residual squares sum), available in Statistica 9.0 (StatSoft, USA) software package. Structural parameters of the degradation function were verified by means of the Student's $t$ test at the 0.01 level of significance. As the accuracy of approximation for the estimated curves to experimental data was accepted by the residual sum of squares (RSS), the coefficient of determination $\left(R^{2}\right)$ can be calculated as the ratio of model variance by total variance and standard error of estimation (SEE):

$S E E=\sqrt{\frac{\mathrm{RSS}}{n-\mathrm{m}}}$

where $n$-number of measurements, $m$-number of structural parameters.

The least squares method was used which was then verified (FOCUS 2006; Kucharski and Sadowski 2009). Minimum residual sum of squares is a criterion of the least squares method. The $\chi^{2}$ test considers the deviations between measured and predicted values to the uncertainty of measurements (FOCUS 2006). The measurement uncertainty is expressed as the percentage of measurement error (err) that is used to scale the mean value being observed:

$\operatorname{err}=\sqrt{\frac{1}{\chi_{\text {tab }}^{2}} \sum \frac{(\mathrm{C}-\mathrm{O})^{2}}{(\overline{\mathrm{O}})^{2}}}$

where $C$ - estimated values, $O$ - observed values, $\bar{O}$ mean value of all observed values, $\chi_{\text {tab }}^{2}$ - tabulated value at the chosen level of significance and degrees of free$\mathrm{dom}=$ number of measurements minus number of model parameters.

The value of test statistics was

$\chi^{2}=\sum \frac{(C-\mathrm{O})^{2}}{(\min . \mathrm{err})^{2}}$

where min. err $=\operatorname{err} / 100 \bar{O}$ is a minimum of scaled error.

If the $\chi^{2}$ value being calculated is less than or equal to the tabulated value, then a separate model is appropriate at the chosen level of significance.

\section{Results and discussion}

The disappearance of linuron in soil samples was analysed in six treatments. These treatments are given in Table 1 with the time for $50 \%$ disappearance of linuron ( $t_{1 / 2}$ using SFO). The results showed that the mixture of linuron with mancozeb in both soils significantly affected persistence of linuron. Other mixtures of

Table 1 Comparison the linuron dissipation time and rate constant in five pesticide mixtures in two soils

\begin{tabular}{|c|c|c|c|c|}
\hline \multirow[t]{2}{*}{ Treatment } & \multicolumn{2}{|l|}{ Sandy loam } & \multicolumn{2}{|l|}{ Clay loam } \\
\hline & $k \pm \mathrm{SE}\left(10^{-2}\right.$ days $\left.^{-1}\right)$ & $t_{1 / 2} \pm 95 \%$ CI (days) & $k \pm \mathrm{SE}\left(10^{-2}\right.$ days $\left.^{-1}\right)$ & $t_{1 / 2} \pm 95 \%$ CI (days) \\
\hline Linuron & $1.88 \pm 0.04$ & $36.9 \pm 1.6$ & $1.55 \pm 0.06$ & $44.4 \pm 3.4$ \\
\hline Linuron + mancozeb & $1.14 \pm 0.07$ & $59.4 \pm 2.5$ & $1.10 \pm 0.07$ & $61.7 \pm 3.8$ \\
\hline Linuron + chlorothalonil & $1.89 \pm 0.03$ & $36.5 \pm 0.8$ & $1.62 \pm 0.04$ & $42.5 \pm 2.5$ \\
\hline Linuron + thiamethoxam & $1.88 \pm 0.03$ & $37.0 \pm 0.6$ & $1.51 \pm 0.08$ & $45.1 \pm 4.4$ \\
\hline Linuron + clothianidin & $1.84 \pm 0.04$ & $37.8 \pm 1.5$ & $1.61 \pm 0.10$ & $42.3 \pm 2.7$ \\
\hline Linuron + thiamethoxam + mancozeb & $1.09 \pm 0.07$ & $63.8 \pm 7.9$ & $1.03 \pm 0.05$ & $67.5 \pm 7.4$ \\
\hline
\end{tabular}

$S E$ standard error, $k$ rate constant, $t_{1 / 2}$ half-life time, $C I$ confidence interval 
linuron with chlorothalonil, thiamethoxam and clothianidin did not have any effect.

During the last experiment, the herbicide concentration decreased in the two soils and was expressed in the exponential model, as shown in Fig. 1.

The studies with a mixture of isoproturon and chlorothanoil showed that interactions between pesticides are possible in soil (Fogg et al. 2003). A mixture of pendimethalin, thiamethoxam and mancozeb significantly inhibited the degradation rate of herbicide pendimethalin (Swarcewicz and Gregorczyk 2012). The study by Wybieralski et al. (2000) and Swarcewicz et al. (2003) showed mancozeb and its mixture with insecticides, such as bromfenvinphos, diazinon and metribuzin to affected respiration and nitrification processes in a loamy sand. The preplant fumigant Vorlex can induce destruction of soil fungi, resulting in an increasing persistence of linuron (Smith 1982). This suggested that mancozeb could influence the biodegradation of other herbicides in soil. Microbial degradation has been shown to be a major source of uncertainty for complex mixture fate prediction. From few studies reported, it may be concluded that the breakdown of major herbicides is not being significantly affected by application in combination with other herbicides, which was confirmed in this study. As examples of the applied expanded statistical analysis of the obtained results, two treatments were selected: linuron alone and in mixture of thiamethoxam plus mancozeb. In sandy loam soil, a significant difference between treatments occurred after
Fig. 1 Comparison of the linuron degradation in sandy loam soil (a) and clay loam soil (b). Fitting of the SFO model: linuron + thiamethoxam + mancozeb (dashed line); linuron only (solid line) to experimental data. Symbols represent mean values of three replications and standard deviations
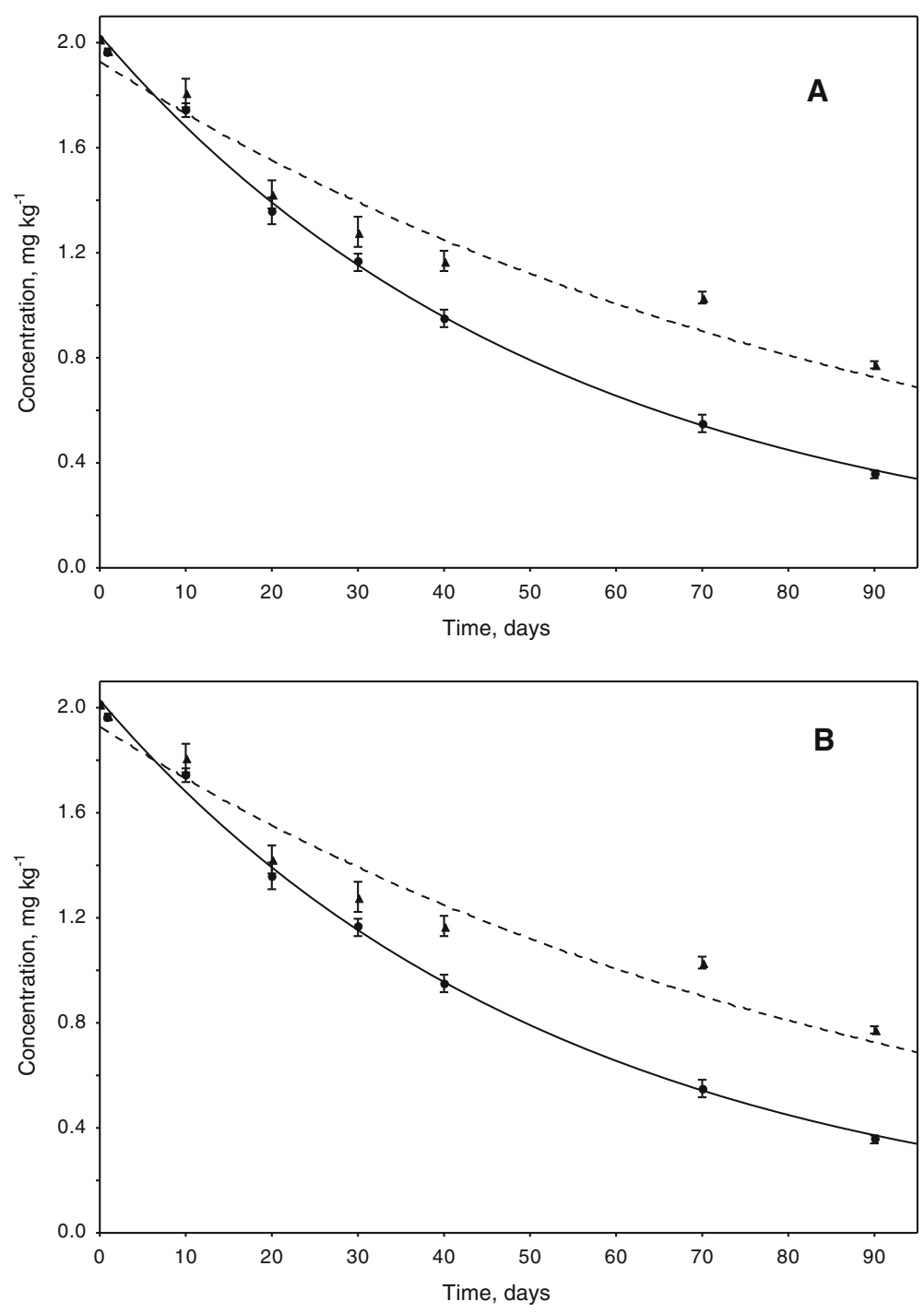

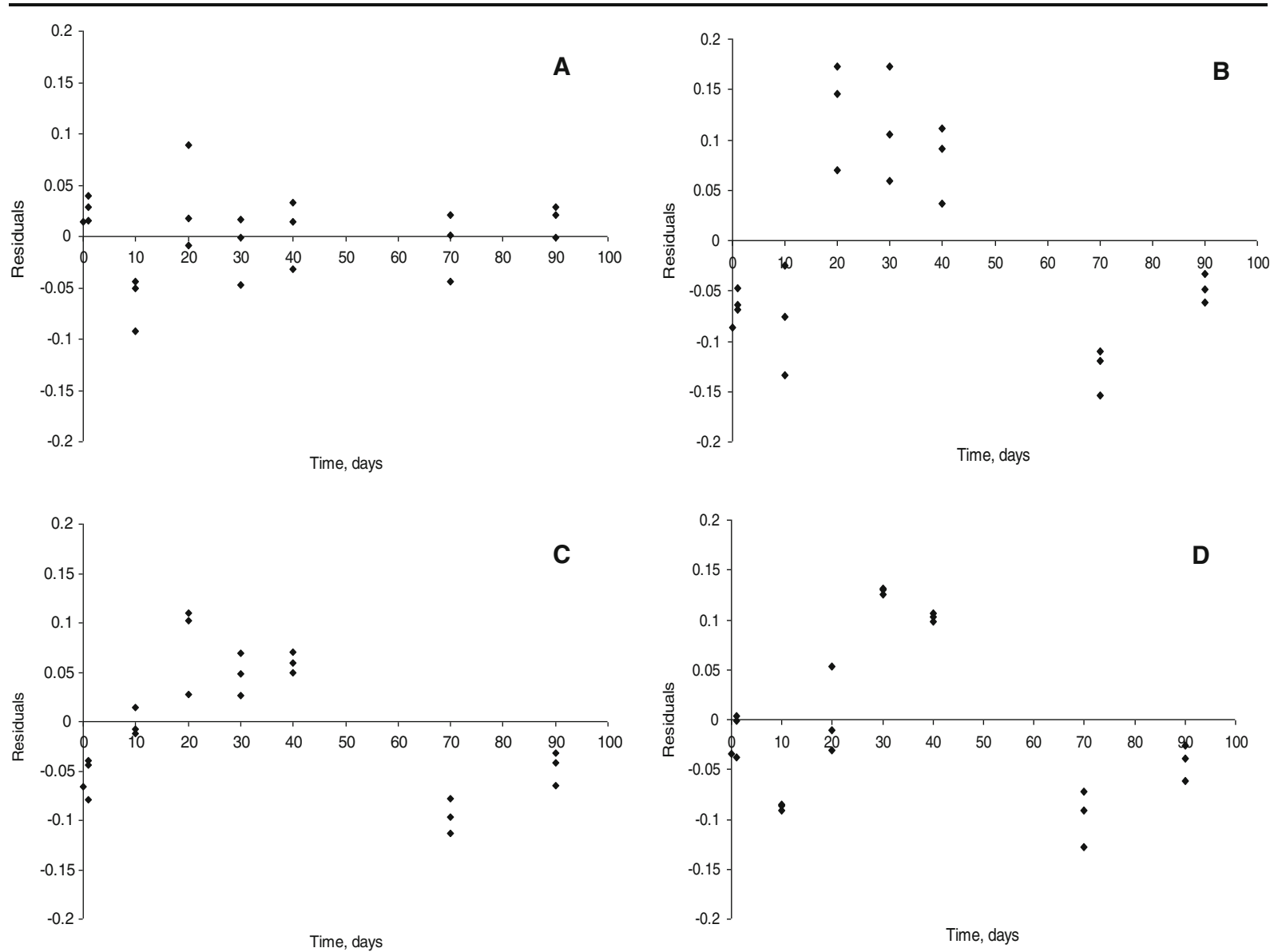

Fig. 2 Residual plot of the SFO model of herbicide degradation in two soils: sandy loam - linuron (a) and linuron + thiamethoxam + mancozeb (b); clay loam-linuron (c) and linuron + thiamethoxam + mancozeb (d)

20 days, while in clay loam, it was observed before that time.
The results of Shapiro-Wilk test (probability level $P>0.05)$ did not give the basis for rejecting the

Table 2 Statistical analysis of the results of the SFO model fitting to experimental data

\begin{tabular}{llllll}
\hline Statistic & Sandy loam & & & \multicolumn{2}{l}{ Clay loam } \\
\cline { 2 - 3 } \cline { 5 - 6 } & Linuron & Linuron + thiamethoxam + mancozeb & & Linuron & Linuron + thiamethoxam + mancozeb \\
\hline RSS & 0.0325 & 0.222 & 0.939 & 0.222 & 0.147 \\
$R^{2}$ & 0.995 & 0.106 & 0.939 & 0.959 \\
SEE & 0.0403 & 1.380 & 6.10 & 0.106 & 0.0857 \\
mean & 1.194 & 0.0842 & 1.380 & 1.439 \\
err & 2.70 & 31.41 & 6.10 & 4.75 \\
min. err & 0.0322 & So do not reject & & 0.0842 & 0.0684 \\
$\chi^{2}$ cal & 31.41 & So do not reject & So & 31.41 & 31.41 \\
$\mathrm{H}_{\mathrm{o}}$ & & & So do not reject & So do not reject
\end{tabular}

$R S S$ residual sum of squares, $R^{2}$ determination coefficient, $S E E$ standard error of estimation, mean mean of observed values, err measurement error percentage, min err scaled error, $\chi^{2}$ cal calculated value of $\chi^{2}$ test, $H_{o}$ null hypothesis 
hypothesis of normal residual distribution. An important assumption of the least squares methods is homoscedasticity of residuals. The difference between the observed value of dependent variable and the predicted value is called a residual (error term). Homoscedasticity requires that the variance of residuals is constant for all observations. If the points in a residual plot are randomly dispersed around the axis of independent values, a regression model is appropriate for these data. The residual plot (Fig. 2) shows a fairly random pattern. This random pattern indicates that the applied regression model provides a decent fit to experimental data.

The goodness of first-order fits to the degradation data was characterised using a combination of visual assessment and a $\chi^{2}$ test being recommended by FOCUS (2006). The results of statistical analysis (Table 2) showed a slightly better fit to the SFO model for linuron in soils $\left(R^{2}=0.983-0.995\right)$ as compared to the pesticide mixture $\left(R^{2}=0.939-0.959\right)$. This ascertainment confirmed other statistics, in particular the value of measurement error percentage (Eq. 2). Calculation of the values of $\chi^{2}$ test (Eq. 3) for type of soil and treatments were the same $\chi^{2}=31.41$. The comparison of this value with that for $\alpha=0.05$ and $\mathrm{df}=22-2=20$ in the statistical table was equal. The values of minimum scaled error were less than the percentage of measurement error, and it was a reason for using Eq. 3. This statistical analysis showed that the null hypothesis cannot be rejected, and the first-order kinetic can be useful for describing the linuron degradation in soil.

Further studies of the persistence of crop protection agents in combinations in soil may provide an insight into the mechanism of degradation of other herbicides and may suggest other ways in which formulations might be modified to control the loss rates.

Open Access This article is distributed under the terms of the Creative Commons Attribution License which permits any use, distribution, and reproduction in any medium, provided the original author(s) and the source are credited.

\section{References}

Beulke, S., Dubus, I. G., Brown, C. D., \& Gottesburen, B. (2000). Simulation of pesticide persistence in the field on the basis of laboratory data. A review. Journal of Environmental Quality, 29, 1371-1379.
FOCUS (2006) Guidance document on estimating persistence and degradation kinetics from environmental fate studies on pesticides in EU registration. Report of the FOCUS Work Group on Degradation Kinetics, EC Document Reference Sanco/10058/2005, Version 1.0. (final draft awaiting approval). European Commission, Brussels

Fogg, P., Boxall, A. B. A., \& Walker, A. (2003). Degradation of pesticides in biobeds: the effect of concentration and pesticide mixtures. Journal of Agricultural and Food Chemistry, 51, 5344-5349.

Kah, M., Beulke, S., \& Brown, C. D. (2007). Factors influencing degradation of pesticide in soil. Journal of Agricultural and Food Chemistry, 55, 4487-4492.

Karanth, N. G. K., Anderson, J. P. E., \& Domsch, K. H. (1984). Degradation of the herbicide diclofop-methyl in soil and influence of pesticide mixtures on its persistence. Journal of Biosciences, 6, 829-837.

Kucharski, M., \& Sadowski, J. (2009). Influence of adjuvants on behavior of phenmedipham in plant and soil. Polskie Journal of Agronomia, 1, 32-36.

McIntyre, B. S., Barlow, N. J., \& Foster, P. M. (2002). Male rats exposed to linuron in utero exhibit permanent changes in anogenitaldistance, nipple retention, and epididymal malformations that result in subsequent testicular atrophy. Toxicological Sciences, 65, 62-70.

Orme S, Kegley S (2006) PAN Pesticide Database, Pesticide Action Network, North America (http://www.pesticideinfo.org)

Sánchez-Camazano, M., Sánchez-Martin, M. J., \& DelgadoPascual, R. (2000). Adsorption and mobility of linuron in soils as influenced by soil properties, organic amendments and surfactants. Journal of Agricultural and Food Chemistry, 48, 3018-3026.

Sánchez-Martin, M. J., Rodriguez-Cruz, M. S., \& SánchezCamazano, M. (2003). Study of the desorption of linuron from soils to water enhanced by the addition of an anionic surfactant to soil-water system. Water Research, 37, 31103117.

Smith, A. E. (1982). Herbicides and the soil environment in Canada. Canadian Journal of Soil Science, 62, 433-460.

Swarcewicz, M., \& Gregorczyk, A. (2012). The effects of pesticide mixtures on degradation of pendimethalin in soils. Environmental Monitoring and Assessment, 184, 3077-3084.

Swarcewicz, M., Jurgiel-Małecka, G., \& Włodarczyk, M. (2003). Influence of some fungicides on respiration and nitrification in the soil. Progress in Plant Protection, 43, 181-184.

U.S. Environmental Protection Agency (U.S. EPA) (1984) Chemical Information Fact Sheet Number 28: Linuron, pp.9-13. Office of Pesticides and Toxic Substances, Washington, DC

U.S. Environmental Protection Agency (U.S. EPA) (1995) R.E.D. Facts Linuron (EPA-738-F-95-003). pp. 1-11 (http://www.epa.gov)

Walker, A. (1970). Effects of quintozene on the persistence and phytotoxicity of chlorpropham and sulfallate in soil. Horticultural Research, 10, 45-49.

Wybieralski, J., Swarcewicz, M., \& Osumek, R. (2000). Side effects of pesticides on respiration and nitrification processes in soil. Zeszyty Probemowe Postepow Nauk Rolniczych, 472, 725-730. 